\title{
A near real-time algorithm for flood detection in urban and rural areas using high resolution Synthetic Aperture Radar images
}

Article

Accepted Version

Mason, D., Davenport, I., Neal, J., Schumann, G. and Bates, P. (2011) A near real-time algorithm for flood detection in urban and rural areas using high resolution Synthetic Aperture Radar images. 2nd International Conference on Space Technology (ICST), 2011. doi: https://doi.org/10.1109/ICSpT.2011.6064673 Available at http://centaur.reading.ac.uk/19723/

It is advisable to refer to the publisher's version if you intend to cite from the work. See Guidance on citing.

To link to this article DOI: http://dx.doi.org/10.1109/ICSpT.2011.6064673

Publisher: IEEE 
All outputs in CentAUR are protected by Intellectual Property Rights law,

including copyright law. Copyright and IPR is retained by the creators or other copyright holders. Terms and conditions for use of this material are defined in the End User Agreement.

\section{www.reading.ac.uk/centaur}

\section{CentAUR}

Central Archive at the University of Reading

Reading's research outputs online 


\section{A near real-time algorithm for flood detection in urban and rural areas using high resolution Synthetic Aperture Radar images}

\author{
D. C. Mason, I. J. Davenport \\ National Centre for Earth Observation \\ University of Reading \\ Reading RG6 6AL, U.K.
}

\author{
J. C. Neal, G. J-P. Schumann, P. D. Bates \\ School of Geographical Sciences \\ University of Bristol \\ Bristol BS8 1SS, U.K.
}

\begin{abstract}
A near real-time flood detection algorithm giving a synoptic overview of the extent of flooding in both urban and rural areas, and capable of working during night-time and day-time even if cloud was present, could be a useful tool for operational flood relief management and flood forecasting. The paper describes an automatic algorithm using high resolution Synthetic Aperture Radar (SAR) satellite data that assumes that high resolution topographic height data are available for at least the urban areas of the scene, in order that a SAR simulator may be used to estimate areas of radar shadow and layover. The algorithm proved capable of detecting flooding in rural areas using TerraSAR-X with good accuracy, and in urban areas with reasonable accuracy.
\end{abstract}

\section{INTRODUCTION}

$\mathrm{F}$ LOODING is a major hazard in both rural and urban areas worldwide, and has occurred regularly in the U.K. in recent times. In particular, there was extensive flooding due to extreme rainfall in the north and west of England in the summer of 2007 that caused a number of deaths and damage of over $£ 3$ Billion. The impact of global warming means that the probability of such extreme rainfall events happening in the future is increasing.

The U.K. Government set up the Pitt Commission to consider what lessons could be learned from the 2007 floods [1]. Among its many recommendations, the Commission highlighted the need to have real-time or near real-time flood visualisation tools available to enable emergency responders to react to and manage fast-moving events, and to target their limited resources at the highest-priority areas. It was felt that a simple GIS that could be effectively updated with timings, level and extent of flooding during a flood event would be a useful system to keep the emergency services informed.

In addition, a near real-time flood extent could be used in conjunction with a hydraulic model of river flood flow to help predict future flood extent. The flood waterline from the image could be intersected with a LiDAR DEM to obtain water surface elevations along the waterline, and these could be assimilated into the model run, correcting the water surface elevations predicted by the model where necessary [2]. This would help to keep the model 'on track', so that its prediction of future flood extent could be viewed with more confidence.
A near real-time flood detection algorithm giving a synoptic overview of the extent of flooding in both urban and rural areas, and capable of working during night-time and day-time even if cloud was present, could thus be a useful tool for operational flood relief management and flood forecasting.

The vast majority of a flooded area may be rural rather than urban, but it is very important to detect the urban flooding because of the increased risks and costs associated with it. Flood extent can be detected in rural floods using SARs such as ERS and ASAR, but these have too low a resolution $(25 \mathrm{~m})$ to detect flooded streets in urban areas. However, a number of SARs with spatial resolutions as high as $3 \mathrm{~m}$ or better have recently been launched that are capable of detecting urban flooding. They include TerraSAR-X, RADARSAT-2, and the four COSMO-SkyMed satellites.

In the absence of significant wind or rain, river floodwater generally appears dark in a SAR image because the water acts as a specular reflector. An automatic near real-time flood detection algorithm using single-polarisation TerraSAR-X data has been implemented in [3] (see also [4]). This searches for water as regions of low SAR backscatter using a region-growing iterated segmentation/classification approach, and is very effective at detecting rural floods, but would require modification to work in urban areas containing radar shadow and layover.

A semi-automatic algorithm for the detection of floodwater in urban areas using TerraSAR-X has also been developed previously [5]. It uses a SAR simulator SETES [6] in conjunction with LiDAR data to estimate regions of the image in which water would not be visible due to shadow or layover caused by buildings and taller vegetation. Ground will be in radar shadow if it is hidden from the radar by an adjacent intervening building. The shadowed area will appear dark, and may be misclassified as water even if it is dry. In contrast, an area of flooded ground in front of the wall of a building viewed in the range direction may be allocated to the same range bin as the wall, causing layover which generally results in a strong return, and a possible misclassification of flooded ground as un-flooded. The algorithm is aimed at detecting flood extents for validating an urban flood inundation model 
in an offline situation, and requires user interaction at a number of stages.

The objective of this work was to build on a number of aspects of the existing algorithms to develop a near real-time algorithm for flood detection in urban and rural areas that is almost completely automatic [7].

\section{DESIGN CONSIDERATIONS}

The algorithm design assumes that high resolution $(\sim 1 \mathrm{~m})$ LiDAR data are available for at least the urban regions in the scene, in order that the SAR simulator may be run in conjunction with the LiDAR data to generate maps of radar shadow and layover in urban areas. The algorithm is therefore limited to urban regions of the globe that have been mapped using airborne LiDAR. However, in the UK most major urban areas in flood-plains have now been mapped, and the same is true for many urban areas in other developed countries.

The approach adopted involves first detecting the flood extent in the rural areas, and then detecting it in the urban areas using a secondary algorithm guided by the rural flood extent [5]. It is well-known in image processing that an improved classification can be achieved by segmenting an image into regions of homogeneity and then classifying them, rather than by classifying each pixel independently using a per-pixel classifier. The use of segmentation techniques provides a number of advantages compared to per-pixel classification. Because of the high resolution of these SARs (up to $1 \mathrm{~m}$ ), individual regions on the ground may have high backscatter variances, reducing the accuracy of per-pixel classifiers. In addition, because the segments created correlate well with real regions of the earth's surface, further object-related features such as object size, shape, texture and context may be used to improve the classification accuracy. The approach used for rural flood detection in [2] and [3] is adopted, which involves segmentation and classification using the eCognition Developer software [8].

In [2] and [3], classification is performed by assigning all segmented homogeneous regions (objects) of the SAR image with mean backscatter less than a given threshold to the class 'flood'. Here the threshold is chosen by using the fact that LiDAR data of the urban area must be available. The LiDAR data will invariably contain water regions giving no LiDAR return because they have acted as specular reflectors that have generated no backscatter at the sensor. These regions can be used as training areas for water (after filtering out high SAR backscatter from small objects such as boats). Similarly, it is possible to select non-water training pixels by searching in un-shadowed areas above the level of the flooding. A simple two-class Bayes classifier using the Probability Distribution Functions (PDFs) for water and non-water can then be used to select the threshold, assuming equal prior probabilities for both classes.

\section{Study AREA AND DATA SET}

The data set used for this study is based upon the 1-in-150 year flood that took place around Tewkesbury, U.K., in July 2007. This resulted in substantial flooding of urban and rural areas, about 1500 homes in Tewkesbury being flooded. Tewkesbury lies at the confluence of the Severn, flowing in from the northwest, and the Avon, flowing in from the northeast. The peak of the flood occurred on July 22, and the river did not return to bank-full until July 31.

On July 25, TerraSAR-X acquired a 3m-resolution StripMap image of the region showing incredible detail of the flooded urban areas (Fig. 1). The TerraSAR-X incidence angle was $24^{\circ}$, and the image was multi-look ground range spatially enhanced. The $\mathrm{HH}$ polarisation mode chosen provided good discrimination between flooded and non-flooded regions. At the time of overpass, there was low wind speed and no rain.

Aerial photos of the flooding were acquired on July 24 and 27 [5], and these were used to validate the flood extent extracted from the TerraSAR-X image. The data set also included LiDAR data ( $2 \mathrm{~m}$ resolution, $0.1 \mathrm{~m}$ height accuracy) of the un-flooded Tewkesbury urban area acquired prior to the flood [5]. In the rural areas, an O.S. Landform Profile DEM generated from 1:10000 map contours and having 10m spatial resolution and $2.5 \mathrm{~m}$ height accuracy was used as an example of a lower resolution, less accurate DEM that might be employed in areas not having LiDAR coverage. Finally, the data set included O.S. Mastermap data of roads, railways and embankments in the area, which would invariably be present in any simple GIS used by the emergency services.

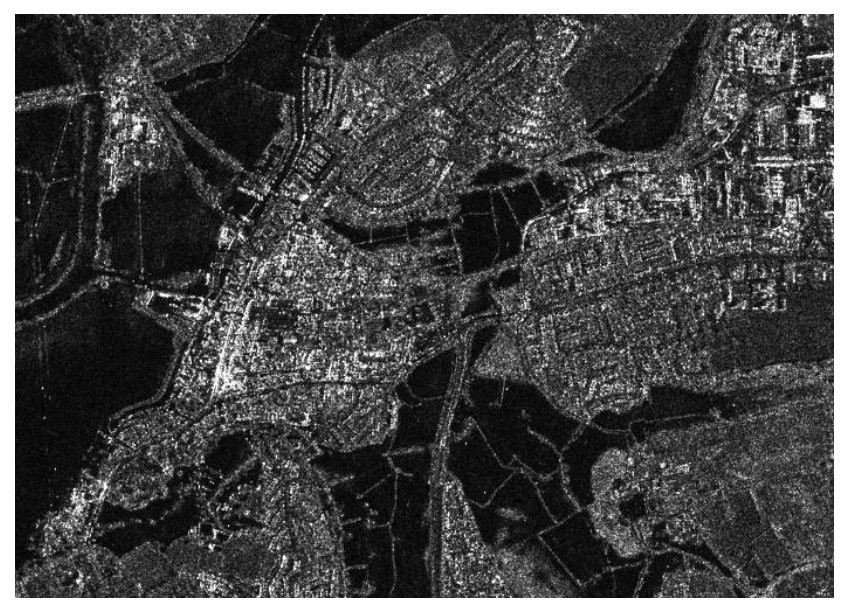

Fig. 1. TerraSAR-X image of Tewkesbury flooding on 25th July 2007 showing urban areas ( $3 \mathrm{~m}$ resolution, $2.6 \times 2 \mathrm{~km}$, dark areas are water, (C) DLR 2007) (after [5]).

\section{METHOD}

The algorithm involves a number of pre-processing operations that can be performed before the geo-registered SAR image has been obtained. The most important of these is the calculation of radar shadow and layover in the urban area. SETES is used in conjunction with the LiDAR data to estimate regions of the SAR image in which water will not be visible due to shadow and layover. Fig. 2 is a binary image produced by SETES showing shadow/layover regions. TerraSAR-X was travelling from north to south and looking west. It can be seen that most shadow/layover occurs in 
streets parallel to the flight direction, whereas streets perpendicular to this have less.

When the SAR image becomes available, the near realtime operations first try to detect the flood extent in the rural area, then use a secondary algorithm to detect it in the urban

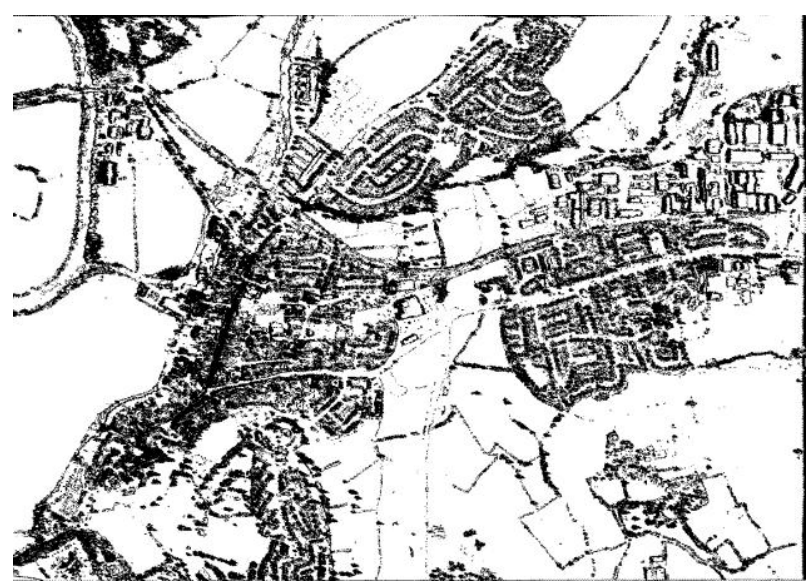

Fig.2. Regions (black) unseen by TerraSAR-X in the LiDAR DSM due to combined shadow and layover (after [5]).

area, guided by the rural flood extent. Rural flood detection is achieved by segmenting the SAR image into homogeneous regions (objects) and then classifying them. Segmentation is performed using the multi-resolution segmentation algorithm of eCognition Developer [8]. Classification is performed by assigning all segmented objects with mean backscatter less than a threshold to the flood class. To determine the threshold, training objects for water and non-water classes are selected automatically. Objects of unassigned height in the LiDAR data that are of relatively large area and low backscatter are used as training areas for water, while un-shadowed objects above the level of the flooding are used as non-water training areas. For the water objects, a histogram of object mean intensities is constructed by weighting the mean intensity of each object by its area. A similar histogram is constructed from the area-weighted mean intensities of the high land objects. Both histograms are normalised to assume equal prior probabilities for each class. The threshold giving the minimum misclassification of water and non-water objects is calculated from the measured histograms. This approach takes into account the fact that objects are being classified rather than the individual pixels making up the objects. This classifies the majority of the rural flooded area correctly. This initial segmentation is then refined using a variety of rules e.g. objects classed as flooded having mean heights above the local flood height are reclassified as un-flooded. Also, different parts of the flooded reach may have different exposures to wind, rain and emergent vegetation, leading to increased backscatter, so that it is unlikely that a single backscatter intensity threshold will be appropriate for all flood objects along the reach. A further refinement involves reclassifying unclassified objects bordering the flood as flooded providing their mean backscatter is less than a slightly raised threshold.
To detect the flooding in the urban area, a simpler regiongrowing algorithm is used, guided by knowledge of the local waterline heights in the adjacent rural area. The urban regiongrowing necessarily differs from the rural segmentation method, because the PDF of flooded urban streets has a substantial tail towards higher backscatter values compared to the PDF of rural water pixels. This is probably due to high backscatter from street furniture such as cars, etc. A set of seed pixels is identified with backscatter less than a threshold. To estimate the threshold, the training areas for water and nonwater identified previously are used to construct histograms of pixel backscatter intensity for these classes. A Bayesian classification is performed, this time on pixels rather than objects, to obtain the threshold giving the minimum misclassification. Seed pixels are also required to have heights less than or similar to the heights of the adjacent rural waterline heights. A local waterline height threshold map is calculated using the rural flood waterlines. It seems reasonable to assume that water in the urban areas should not be at a substantially higher level than in the nearby rural areas. However, unless a height threshold is imposed, there could be a substantial false positive rate of water at higher levels [5]. The spatial variability of this threshold reflects the fact that different parts of the area can be flooded to different heights. Finally, seed pixels are clustered together provided that they are close to other seed pixels. Regions of shadow and layover are masked out in the processing.

\section{RESUlts}

The flood extent estimated by TerraSAR-X in the urban and rural areas was validated using the flood extent estimated from the aerial photos. Details are given in [7]. In the urban area in Fig. 1, 75\% of the urban water pixels visible to TerraSAR-X were correctly detected. However, this percentage reduced somewhat if the urban flood extent visible in the aerial photos and detected by TerraSAR-X was considered, because flooded pixels in the shadow/layover areas not visible to TerraSAR-X then had to be taken into account. The accuracy of flood detection in rural areas was assessed using data over a separate rural validation area, and almost $90 \%$ of water pixels in this area were correctly detected by TerraSAR-X.

Fig. 3 shows a possible multi-scale visualisation of the flood extents in the rural and urban areas, with flooding shown as blue in the rural area and yellow in the urban area. Regions coloured brown in the urban area are areas of shadow/layover that are below the waterline height threshold, and therefore may or may not be flooded, as effectively they cannot be imaged by TerraSAR-X.

\section{OPERATIONAL CONSIDERATIONS}

In order to obtain a high resolution satellite SAR image of a developing flood, it would be necessary immediately after a storm forecast had been issued to initiate operations similar to those involved in an invocation of the International Charter "Space and Major Disasters". When the Charter is invoked, Space Agencies around the world direct their satellites to image the flooding if possible. Current practice usually involves 
waiting until the disaster has developed somewhat before initiating the imaging, but this would need to be modified to invoke imaging immediately after the storm forecast had been issued.

In order to ensure that a SAR image was obtained in near real-time, it would be necessary to minimise the time delay between an overpass and the production of the resulting SAR flood extent. The pre-processing operations could be carried

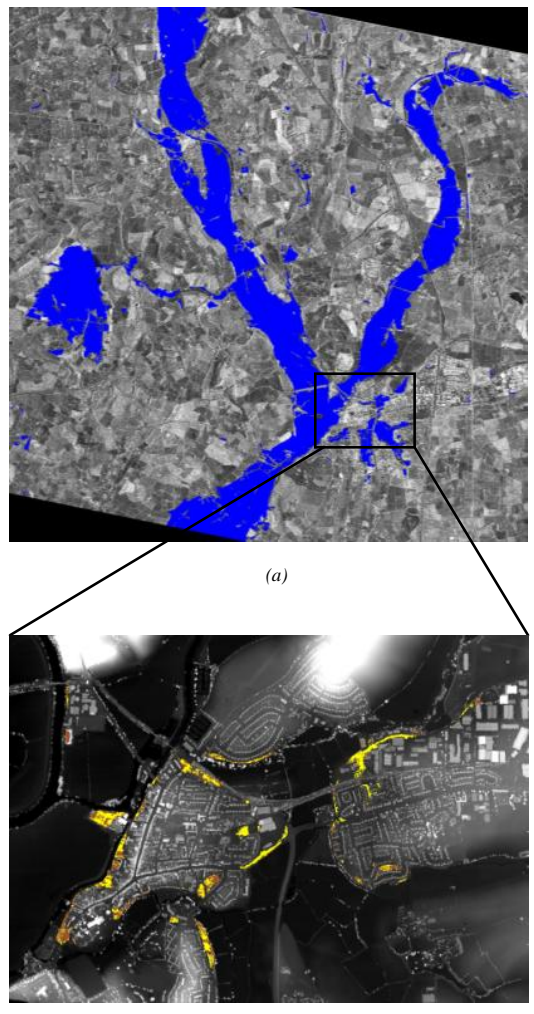

(b)

Fig. 3. Possible multi-scale visualisation of flood extents in (a) rural (blue = predicted flood), and (b) urban areas (yellow = predicted flood, brown $=$ shadow/layover areas that may be flooded (after [7])).

out in parallel with tasking the satellite to acquire the image of flooding. Considering TerraSAR-X as an example, TerraSAR-X allows satellite tasking twice a day, so that the shadow/layover map could be generated prior to the image acquisition by running SETES on the LiDAR data given the SAR trajectory and proposed look angle. The DEM and vegetation height map could be generated off-line at an earlier date, and retrieved between satellite tasking and image acquisition. Download of the image to the ground station, followed by near real-time processing of the raw SAR data to a multilook image, automatic geo-registration and delineation of the flood extent, could in theory be carried out within a few hours after overpass. For example, it is known that raw TerraSAR$\mathrm{X}$ images of the UK can be downloaded to the ground station, processed to multi-look images, and geo-registered to Enhanced Ellipsoid Corrected (EEC) form ready for download to the user in about 4 hours after acquisition, though this facility would currently only appear to be available to scientific users of TerraSAR-X data. A blueprint of the operational sys- tem required for near real-time supply of geo-located high resolution SAR data to users is provided by the FAIRE system developed at ESA-ESRIN, which is able to provide users with processed ENVISAT ASAR and ERS-2 SAR images approximately 3 hours after acquisition [9]. As far as is known, such systems have still to be developed for high resolution SAR images.

The time to run the various near real-time processing steps in the flood delineation on a $3 \mathrm{GHz}$ desktop PC was about 20 minutes for the sub-image of Fig. $3(6750 \times 6000$ pixels), and could be significantly reduced using additional eCognition processing nodes [8].

\section{CONCLUSION}

An automatic near real-time flood delineation algorithm has been developed that is capable of detecting flooding in rural areas with good accuracy, and in urban areas with reasonable accuracy. While good classification accuracy was obtained in rural areas, the accuracy was reduced in urban areas partly because of TerraSAR-X's restricted visibility of the ground surface due to shadow and layover. A limitation of this work is that it is based on data from a single flood event. Even though the scene involved contains a large area with many example situations, the algorithm needs to be tested further using other events.

\section{ACKNOWLEDGMENT}

This work was supported by NERC grant NE/I000658/1 and EPSRC grant EP/F020511/1. Thanks are due to the Environment Agency of England and Wales for the provision of LiDAR data.

\section{REFERENCES}

[1] M. Pitt, "Learning lessons from the 2007 floods. U.K," Cabinet Office Report, June 2008 .

[2] J.C. Neal, G.J-P. Schumann, P.D. Bates and D.C. Mason, "Estimating river discharge with hydraulic models and remote sensing," unpublished.

[3] S. Martinis, A. Twele and S. Voigt, "Towards operational near realtime flood detection using a split-based automatic thresholding procedure on high resolution TerraSAR-X data," Natural Hazards and Earth System Sciences, vol. 9, pp. 303-314, 2009.

[4] S. Martinis, A. Twele and S. Voigt, "Unsupervised extraction of floodinduced backscatter changes in SAR data using Markov image modeling on irregular graphs," IEEE. Trans. Geoscience Rem. Sens., vol. 49, no. 1 , pp. 251-263, 2011 .

[5] D.C. Mason, R. Speck, B. Devereux, G. Schumann, J. Neal and P.D. Bates, "Flood detection in urban areas using TerraSAR-X," IEEE. Trans. Geoscience Rem. Sens., vol. 48, no. 2, pp.882-894, 2010.

[6] R. Speck, P. Turchi and H. Süß, "An end-to-end simulator for highresolution spaceborne SAR systems," Proc. SPIE Defense and Security, vol. 6568,2007

[7] D.C. Mason, I.J. Davenport, J.C. Neal, G.J-P. Schumann and P.D. Bates, "Near real-time flood detection in urban and rural areas using high resolution synthetic aperture radar images," unpublished.

[8] Definiens AG : Definiens Developer 8 User Guide, Document Version 1.2.0, Munich, Germany, 2009.

[9] R. Cossu, E. Schoepfer, Ph. Bally and L. Fusco, "Near real-time SAR based processing to support flood monitoring," J. Real-Time Image Processing, vol. 4, no. 3, pp. 205-218, 2009. 